\title{
Pregnancy outcomes in non-gynecological and non-hematological cancers: a retrospective cohort
}

\author{
Minakshi Kumari' ${ }^{1}$, Hilda Yenuberi ${ }^{1}$, Swati Rathore ${ }^{1}$, Deepak Abraham ${ }^{2}$, V. T. K. Titus ${ }^{3}$, \\ Jiji Elizabeth Mathews ${ }^{1}$, Ashish Singh ${ }^{4 *}$
}

\begin{abstract}
${ }^{1}$ Department of Obstetrics and Gynecology, Christian Medical College Hospital, Vellore, Tamil Nadu, India ${ }^{2}$ Department of Surgery, Christian Medical College Hospital, Vellore, Tamil Nadu, India ${ }^{3}$ Department of Orthopedics, Christian Medical College Hospital, Vellore, Tamil Nadu, India ${ }^{4}$ Department of Medical Oncology, Christian Medical College Hospital, Vellore, Tamil Nadu, India
\end{abstract}

Received: 24 December 2019

Revised: 24 January 2020

Accepted: 29 January 2020

\section{*Correspondence:}

Dr. Ashish Singh,

E-mail: coronistrial@yahoo.co.in

Copyright: (C) the author(s), publisher and licensee Medip Academy. This is an open-access article distributed under the terms of the Creative Commons Attribution Non-Commercial License, which permits unrestricted non-commercial use, distribution, and reproduction in any medium, provided the original work is properly cited.

\begin{abstract}
Background: Of all the cancers in women, about $10 \%$ manifest in the reproductive age group. These can be broadly classified as gynaecological cancers and non-gynaecological cancers; Among the non-gynaecological cancers besides haematological cancer, breast, thyroid, colon, bone and CNS are seen rarely. Clinical acumen in diagnosis and management of these rare cancers that appear during pregnancy or before pregnancy are difficult due to insufficient guidelines and rarity of the conditions.

Methods: A retrospective analysis of rare cancers during a period of 10 years in this hospital was performed. Data concerning the gestational age at delivery, birth weight, mode of delivery and complications and the management of the cancers during the pregnancy were collected.

Results: Among the 41 women with these rare non-gynecological, non-hematological cancers, 13 pregnancies were in women with prior history of cancers and 28 pregnancies were with current history of cancer. Majority of these cases with prior history were thyroid cancers who had uneventful pregnancies and delivered normally. Among pregnancies with current history of cancer, breast, CNS, GIT, and head and neck were the cancers with 5-6 cancers in each category. About 50\% of these cancers were delivered early between 31-35 weeks to facilitate optimal treatment. Cancers with guarded prognosis diagnosed before 20 weeks had a termination of pregnancy.

Conclusions: Cancers during pregnancies are rare and their care must be individualized.
\end{abstract}

Keywords: Breast, Cancer, Central nervous system, Pregnancy, Thyroid

\section{INTRODUCTION}

Cancer is said to be the disease of the elderly. According to the worldwide cancer data in 2018, 18 million patients with cancers were identified, of whom 8.5 million cancers were among women. ${ }^{1}$ The common cancers among women are breast, thyroid, colorectal and lung, averaging to $43.9 \%$ of all the cancers. ${ }^{1}$ Among the reproductive age group, about 35000 women develop cancer every year and $0.1 \%$ of pregnancies are affected by cancers. ${ }^{2,3}$ Due to the advancement in the available treatments for cancer and improved 5-year survival rates there may be increasing number of cancer survivors who are able to achieve pregnancies. Cancers in women can be broadly classified as gynaecological and nongynaecological cancers. Among the non-gynaecological cancers majority of studies have looked at outcomes of pregnancies associated with common cancers such as 
melanoma, lymphomas and leukemia. ${ }^{4}$ Nongynaecological and non-haematological cancers form a minority of these cancers. Clinical experience, diagnosis and management of these cancers that appear during pregnancy is difficult due to insufficient guidelines and rarity of the condition. Therefore, retrospective data that is available could provide useful information on clinical presentation and management of these cases. This could improve the care that can be offered to the mother, thereby ensuring a safe pregnancy and a healthy fetus and neonate. The aim of this study was to analyse the pregnancy management and outcome in women with past or current non-gynaecological and non-haematological cancers.

\section{METHODS}

This retrospective cohort study of antenatal women with past or present history of non-gynecological and nonhematological cancers seen over 10 years between 2008 to 2019 was done in a large tertiary Centre. The Institutional Review Board and Ethics Committee (IRB:12030 Retro) of Christian Medical College and Hospital (CMCH), Vellore, India had approved the study.

\section{Inclusion criteria}

- Pregnant women with past or present history of nongynecological and non-hematological cancers who had come to $\mathrm{CMC}$ for further evaluation and treatment.

\section{Exclusion criteria}

- Pregnant women with gynecological and hematological cancers and non-pregnant women with non-gynecological and non-hematological cancers.

The details of the study participants were obtained from the electronic medical records and inpatient and outpatient charts using keywords like pregnancy, nongynecological cancers, thyroid cancer, breast cancer, gastrointestinal tract cancers, renal cancer, Bone and soft tissue tumors, CNS tumors. Hundred charts of women in the reproductive age with cancers were obtained from the medical records department of which only seventy inpatient and outpatient charts were pregnancies with malignancies. Of these forty-one women with past or present history of non-gynecological and nonhematological cancers affected with pregnancies were identified. Therefore, the study population were these 41 women. Information regarding their demographic details, type of cancer, treatment received or ongoing treatment and gestational age at diagnosis was obtained. Information regarding the pregnancy like need for termination, gestational age at delivery, and mode of delivery were collected. Past history of cancer was considered when the diagnosis and treatment for cancer was completed prior to the onset of pregnancy and was in remission. Present history of cancer was defined as cancer diagnosed in the ongoing pregnancy or if pregnancy occurred while under treatment for cancer.

\section{Statistical analysis}

Statistical analysis of all the categorical variables in this research was summarized using counts and percentages.

\section{RESULTS}

Pregnancies of 41 women with non-gynaecological or non-haematological cancer prior to pregnancy or during pregnancy were included (Table 1). The mean age of the 41 women was 26.9 years (19-39). Twenty-four women were primigravidae and seventeen women were multigravidas. Thirteen women had prior history of cancer and twenty-eight women had cancer during pregnancy. Among the thirteen women with prior history of cancer, eight cases were thyroid cancers, two were head and neck, one was central nervous system and two were of the gastrointestinal tract. The median duration of years between the treatment of cancer and the pregnancy was 3 years (range 1-19 years) Among the eight women with thyroid cancer before pregnancy all had normal deliveries with an average baby weight of $2.7 \mathrm{kgs}$. None of them had any major complications. All the women with other cancers prior to pregnancies also delivered normally.

Among the 28 cancers during pregnancy, six were breast cancers, three thyroid cancers, five central nervous system cancers, four cancers of the gastrointestinal tracts, three of the head and neck, three of the bone and soft tissue, two renal and two others i.e. a case of leiomyosarcoma and neuroendocrine tumor. Among the women with cancer during pregnancy, the mean gestational age of diagnosis was 17 weeks. Details of the mode of management and outcome are elaborated in the Table. Among the 28 cases of cancer during pregnancy the commonest was breast cancer. Four women with breast cancer had three to four cycles of chemotherapy during pregnancy. The chemotherapeutic agents used in cases with Breast cancer were doxorubicin, docetaxel and cyclophosphamide. Two delivered normally and three had caesarean section between 33-35 weeks to facilitate adjuvant therapy. One pregnancy was terminated at 11 weeks. Among the three women with thyroid cancer during pregnancy, two had termination of pregnancy to receive iodine ablation and one woman delivered at term and received iodine ablation after delivery. Details of pregnancy outcomes of the other cancers during pregnancy is described in the Table. Three cases of bone and soft tissue were delivered at 31-33 weeks by caesarean section to facilitate adjuvant therapy or palliative care. Both the women with renal cell cancer had uneventful pregnancies and delivered normally at term. All women who were delivered before 34 weeks were given Betamethasone to improve lung maturity in the neonate. 
Table 1: Frequency of non-gynaecological and non- haematological cancers and pregnancy and their treatment.

\begin{tabular}{|c|c|c|c|c|c|c|c|}
\hline Cancer type & Frequency & $\begin{array}{l}\text { Cancer before } \\
\text { pregnancy } \\
(\mathbf{n}=13)\end{array}$ & $\begin{array}{l}\text { Pregnancy } \\
\text { outcome }\end{array}$ & $\begin{array}{l}\text { Treatment } \\
\text { type prior to } \\
\text { pregnancy }\end{array}$ & $\begin{array}{l}\text { Cancer during } \\
\text { pregnancy } \\
(\mathbf{n}=\mathbf{2 8})\end{array}$ & $\begin{array}{l}\text { Treatment type } \\
\text { during or after } \\
\text { pregnancy }\end{array}$ & $\begin{array}{l}\text { Pregnancy } \\
\text { outcome }\end{array}$ \\
\hline Thyroid & $11(26.8 \%)$ & 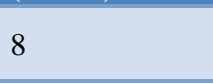 & $8 \mathrm{ND}^{1 *}$ & $\begin{array}{l}7{ }^{2} \mathrm{~S}_{\mathrm{x}}+{ }^{3} \mathrm{IA} \\
1 \mathrm{~S}_{\mathrm{x}}\end{array}$ & ( & $\begin{array}{l}2 S_{x}+I A \\
1 S_{x}\end{array}$ & $\begin{array}{l}2^{4} \mathrm{TOP} \\
1 \mathrm{ND}\end{array}$ \\
\hline Breast & $6(14.6 \%)$ & 0 & - & ה & 6 & $\begin{array}{l}3 \mathrm{~S}_{\mathrm{x}}+{ }^{6} \mathrm{CT}+{ }^{7} \mathrm{RT} \\
1 \mathrm{~S}_{\mathrm{x}}+\mathrm{CT} \\
1 \mathrm{~S}_{\mathrm{x}} \\
1 \mathrm{CT}\end{array}$ & $\begin{array}{l}2 \mathrm{ND} \\
3{ }^{5} \mathrm{LSCS} \\
1 \mathrm{TOP}\end{array}$ \\
\hline${ }^{8} \mathrm{CNS}$ & $6(14.6 \%)$ & 1 & $1 \mathrm{ND}$ & $\mathrm{S}_{\mathrm{x}}$ & 5 & $\begin{array}{l}2 \mathrm{~S}_{\mathrm{x}}+\mathrm{CT}+\mathrm{RT} \\
2 \mathrm{~S}_{\mathrm{x}}+\mathrm{RT} \\
1 \mathrm{CT}+\mathrm{RT}\end{array}$ & $\begin{array}{l}2 \mathrm{ND} \\
1 \mathrm{LSCS} \\
1 \mathrm{TOP} \\
1{ }^{10} \mathrm{LTF}\end{array}$ \\
\hline${ }^{9} \mathrm{GIT}$ & $6(15 \%)$ & 2 & 2 ND & $S_{x} \pm C T$ & 4 & $4 S_{x}$ & $\begin{array}{l}2 \mathrm{ND} \\
1 \mathrm{TOP} \\
1 \mathrm{LTF}\end{array}$ \\
\hline Head and neck & $5(12 \%)$ & 2 & $2 \mathrm{ND}$ & $2 S_{x}+R T$ & 3 & $\begin{array}{l}2 \mathrm{CT} \\
1 \mathrm{~S}_{\mathrm{x}}\end{array}$ & $\begin{array}{l}2 \mathrm{ND} \\
1 \mathrm{LTF}\end{array}$ \\
\hline $\begin{array}{l}\text { Bone }+ \text { soft } \\
\text { tissues }\end{array}$ & $3(7 \%)$ & 0 & - & - & 3 & $\begin{array}{l}2 S_{x}+C T \\
1 \mathrm{CT}\end{array}$ & $3 \mathrm{LSCS}$ \\
\hline Renal & $2(5 \%)$ & 0 & - & - & 2 & $S_{\mathrm{x}}$ & $\begin{array}{l}2 S_{x} \\
2 \mathrm{ND}\end{array}$ \\
\hline Others & $2(5 \%)$ & 0 & - & - & 2 & $\begin{array}{l}1 \mathrm{~S}_{\mathrm{x}}+\mathrm{CT}+\mathrm{RT} \\
1 \mathrm{~S}_{\mathrm{x}}+\mathrm{CT}\end{array}$ & NA \\
\hline
\end{tabular}

${ }^{1} \mathrm{ND}$ - Normal delivery, ${ }^{2} \mathrm{Sx}$ - Surgery, ${ }^{3} \mathrm{IA}$ - Iodine ablation, ${ }^{4} \mathrm{TOP}$ - Termination of pregnancy, ${ }^{5} \mathrm{LSCS}$ - Lower segment caesarean section,

${ }^{6} \mathrm{CT}$ - Chemotherapy, ${ }^{7} \mathrm{RT}$ - Radiotherapy, ${ }^{8} \mathrm{CNS}$ - Central nervous system, ${ }^{9} \mathrm{GIT}$ - Gastrointestinal tract, ${ }^{10} \mathrm{LTF}$ - Lost to follow-up.

The histopathology of all cases of thyroid were follicular variant of papillary carcinoma. The histopathology of breast cancers was infiltrative ductal cancer. In the CNS cancers the histopathology was gliomas, meningiomas and a case of hemangiopericytoma. The histopathology of the gastrointestinal system were cases of adenocarcinomas and a case hepatocellular cancer. The cancers of the head and neck were that of the hypo pharynx salivary gland and tongue. The cancer of the bones were Ewing sarcoma and osteosarcoma. Both the cancers of kidney were renal cell carcinoma.

\section{DISCUSSION}

This retrospective cohort study was done to assess the profile of patients with pregnancies affected by nongynecological and non-hematological cancers. More than half of this study population had cancer diagnosed during a pregnancy. Of the remaining patients the median duration of time to conceive following malignancy was 3 years which was almost similar to a study done by Timur et al, who had found a median duration of 3.8 years. ${ }^{5}$

Most of the women affected by thyroid cancer had completed the treatment by surgery and radioactive iodine ablation prior to the pregnancy and it was seen that the treatment per se had no effect on the outcome of pregnancy. Though progression of papillary carcinoma is slow two of the three women who presented with thyroid cancer during early pregnancy opted to have the pregnancy terminated.
During the study we did not find any pregnancy in a breast cancer survivor probably because the cumulative incidence of live births in these patients is as low as $8 \%$ in 10 years according to a study done by Anderson et al. ${ }^{6}$ This could be secondary to the harmful effects of the chemotherapeutic agents which reduced the ovarian reserve. However, treatment for breast cancer during a pregnancy with chemotherapeutic agent like doxorubicin, docetaxel and cyclophosphamide did not show any adverse effects on the pregnancy or fetus in terms of prematurity or growth restriction. These chemotherapeutic agents are recommended to be used in the second and third trimesters and Taxane group drugs are better avoided but could be given depending on the disease status after the first trimester. ${ }^{3}$ In this study majority of women with breast cancer were allowed to continue pregnancy as it is seen that treatment delays due to pregnancy did not have an adverse effect on the outcome of breast cancer and studies have not shown that terminating a pregnancy improves a woman's prognosis. ${ }^{7}$

Central nervous system malignancies during pregnancy is again rare. The type of malignancies in decreasing frequencies are gliomas, meningiomas and neuroma. ${ }^{8}$ Hemangiopericytomas are the rarest which account for $<1 \%$ of all tumors and are more common in men. ${ }^{9}$ In this study of the 6 patients with CNS tumors, 2 patients had anaplastic ependymoma and the others had neuroma, oligodendroglioma, oligoastrocytoma, hemangiopericytoma. Of these patients, one had past history of cancer who went through 2 uneventful pregnancies and delivered babies of average weight at term. 2 of the other 
5 patients with pregnancy complicated by brain tumors were followed up till period of viability was achieved and one was delivered vaginally and the other underwent caesarean section for obstetric reason, in order to continue optimal treatment. This is in contrast to a population-based study done over 20 years, where Terry et al have found a strong association between brain tumors and caesarean section $(\mathrm{p}<0.0001) .{ }^{8}$ In relation to gastrointestinal tumors, it was seen that past history of cancer or early cancer during an ongoing pregnancy had favorable outcome on the pregnancy.

Among the 3 patients with musculoskeletal tumors, which is very rare in pregnancy, one pregnancy had to be terminated as the patient had recurrent sarcoma and the other 2 pregnancies were delivered between 33-34 weeks. ${ }^{10}$ According to Figueiro-Filho et al, preterm birth and fetal growth restriction were common associations. ${ }^{11}$ In this study preterm birth was seen but fetal growth restriction was not seen. Chemotherapeutic agents like Vincristine, Adriyamicin and Cyclophosphamide was used for one woman during pregnancy.

In this study cohort the chemotherapeutic agents used during pregnancy were Doxorubicin, Cyclophosphamide, Taxanes, Etoposide, Vincristine. According to Cardonick et al, the cognitive assessment, school performance and behavioral competence of the children of cancer patients who were exposed to these agents was comparable to the children of cancer patients who were not exposed. ${ }^{12}$ The major limitation of this study was that it was a retrospective study and all information was not available. The cancers covered in this study had varied prognosis. However, from the available information in this study, pregnant women with prior history of malignancy were mainly thyroid cancers that are known to have good prognosis. These women had uncomplicated deliveries and most of them delivered normally. Pregnant women with malignancies associated with guarded prognosis were terminated when the woman presented before 20 weeks and delivered early by 31-34 weeks if the woman presented after 20 weeks. Early delivery facilitated access to optimal treatment and several women delivered normally.

This research reiterates the need for national registries of rare cases to be maintained to make meaningful inferences from the cases managed.

\section{ACKNOWLEDGMENTS}

Authors would like to thank all staffs involved with the care of the patients.
Funding: No funding sources

Conflict of interest: None declared

Ethical approval: The study was approved by the Institutional Ethics Committee

\section{REFERENCES}

1. Worldwide cancer data. World Cancer Research Fund, 2018. Available at: https://www.wcrf.org/dietandcancer/cancertrends/worldwide-cancer-data. Accessed on $10^{\text {th }}$ December 2019.

2. Coccia PF. Overview of adolescent and young adult oncology. J Oncol Pract. 2019:235-7.

3. Botha $\mathrm{MH}$, Rajaram S, Karunaratne K. Cancer in pregnancy. Int J Gynecol Obstet. 2018;143(S2):13742.

4. Pavlidis NA. Coexistence of pregnancy and malignancy. The Oncol. 2002;7(4):279-87.

5. Timur H, Tokmak A, Iskender c, Yildiz ES, Inal HA, Uygur D, et al. Obstetric outcomes in nongynecologic cancer patients in remission. Eurasian $\mathbf{J}$ Med. 2016;48(2):130-4.

6. Anderson C, Engel SM, Anders CK, Nichols HB. Live birth outcomes after adolescent and young adult breast cancer. Int J Cancer. 2018;142(10):1994-2002.

7. Durrani S, Akbar S, Heena H. Breast cancer during pregnancy. Cureus. 2018;10(7):e2941.

8. Terry AR, Barker FG, Leffert L, Bateman BT, Souter I, Plotkin SR. Outcomes of hospitalization in pregnant women with CNS neoplasms: a populationbased study. Neuro-Oncol. 2012;14(6):768-76.

9. Kumar N, Kumar R, Kapoor R, Ghoshal S, Kumar P, Salunke PS, et al. Intracranial meningeal hemangiopericytoma: 10 years-experience of a tertiary care Institute. Acta Neurochir (Wien). 2012;154(9):1647-51.

10. Postl LK, Gradl G, von Eisenhart-Rothe R, Toepfer A, Pohlig F, Burgkart R, et al. Management of musculoskeletal tumors during pregnancy: a retrospective study. BMC Womens Health. 2015;15(1):48.

11. Fiueiro-Filho EA, Al-Sum H, Parrish J, Wunder JS, Maxwell C. Maternal and fetal outcomes in pregnancies affected by bone and soft tissue tumors. AJP Rep. 2018;8(4):e343-8.

12. Cardonick EH, Gringlas MB, Hunter K, Greenspan J. Development of children born to mothers with cancer during pregnancy: comparing in utero chemotherapy-exposed children with nonexposed controls. Am J Obstet Gynecol. 2015;212(5):658-e1.

Cite this article as: Kumari M, Yenuberi $\mathrm{H}$, Rathore S, Abraham D, Titus V.T.K., Mathews JE, et al. Pregnancy outcomes in non-gynecological and nonhematological cancers: a retrospective cohort. Int J Reprod Contracept Obstet Gynecol 2020;9:1106-9. 